\title{
PENGARUH PENGETAHUAN NASABAH DAN KUALITAS LAYANAN TERHADAP MINAT INDIVIDU PENGGUNA INTERNET BANKING BANJARMASIN
}

\author{
Sri Bulkia*, Ana Sofia Herawati, Nurul Hasanah \\ Universitas Islam Kalimantan Muhammad Arsyad Al-Banjari \\ Jl. Adhyaksa No. 2 Kayutangi Banjarmasin \\ e-mail: kiasyah30@gmail.com
}

\begin{abstract}
The very rapid development in the banking world today makes the banking industry compete in providing services to its customers. Among them are digital based services such as internet banking. Bank X as a government bank also applies internet banking services. Bank $X$ internet banking services have carried out various types of development but there are still many customers who feel dissatisfied. This study aims to determine how the influence of customer knowledge on individual internet users 'interests, the influence of service quality on individual internet users' user interests, the influence of customer knowledge and service quality on the individual interests of internet banking users. The type of research used is quantitative research with a survey approach. This study involved 60 respondents as a sample of research and sampling using stratified random sampling. The type of data used in this study is primary data obtained from questionnaires distributed to Bank $X$ bank customers and secondary data in the form of documentation, literature, and internet. The data analysis technique used in this study is multiple regression analysis. The results of data analysis show that customer knowledge has a significant influence on the interest of internet banking users, service quality significantly affects individual interests of internet banking users, customer knowledge and service quality simultaneously have a significant effect on the interest of internet banking users. The implication of this study is that customer knowledge and service quality have an equally important role both individually and simultaneously in increasing the interest of internet banking users.
\end{abstract}

Keywords: Customer Knowledge, Service Quality, Individual Interest, Internet Banking

\begin{abstract}
Abstrak
Perkembangan yang sangat pesat di dunia perbankan saat ini membuat industri perbankan bersaing dalam memberikan layanan kepada para pelanggannya. Diantaranya adalah layanan berbasis digital seperti internet banking. Bank X sebagai bank pemerintah juga menerapkan layanan internet banking. Layanan internet banking Bank X telah melakukan berbagai jenis pengembangan tetapi masih banyak nasabah yang merasa tidak puas. Penelitian ini bertujuan untuk mengetahui bagaimana pengaruh pengetahuan pelanggan terhadap minat pengguna internet individu, pengaruh kualitas layanan terhadap minat pengguna pengguna internet individu, pengaruh pengetahuan pelanggan dan kualitas layanan terhadap minat individu pengguna internet banking. Jenis penelitian yang digunakan adalah penelitian kuantitatif dengan pendekatan survei. Penelitian ini melibatkan 60 responden sebagai sampel penelitian dan pengambilan sampel menggunakan stratified random sampling. Jenis data yang digunakan dalam penelitian ini adalah data primer yang diperoleh dari kuesioner yang dibagikan kepada nasabah bank Bank X dan data sekunder dalam bentuk dokumentasi, literatur, dan internet. Teknik analisis data yang digunakan dalam penelitian ini adalah analisis regresi berganda. Hasil analisis data menunjukkan bahwa pengetahuan pelanggan memiliki pengaruh signifikan terhadap minat pengguna internet banking, kualitas layanan secara signifikan mempengaruhi minat individu pengguna internet banking, pengetahuan pelanggan dan kualitas layanan secara simultan berpengaruh signifikan terhadap minat pengguna internet banking. Implikasi dari penelitian ini adalah bahwa pengetahuan pelanggan dan kualitas layanan memiliki peran yang sama pentingnya baik secara individu maupun secara bersamaan dalam meningkatkan minat pengguna internet banking.
\end{abstract}

Kata kunci: Pengetahuan Pelanggan, Kualitas Layanan, Minat Perorangan, Perbankan Internet 


\section{PENDAHULUAN}

Terhitung sejak fase awal perkembangan internet di Indonesia tahun 1990 an, jumlah pengguna internet meningkat pesat. Namun peningkatan ini tidak dibarengi dengan pemerataan pengguna internet di Indonesia secara geografis. Menurut riset Asosiasi Penyelenggara Jasa Internet Indonesia (APJII), dan didukung banyak sumber lainnya, pengguna internet Indonesia hidup di wilayah Barat, khususnya pulau Jawa. Gambaran ini juga merefleksikan ketidakmerataan kesejahteraan warga negara Indonesia secara keseluruhan.

Berdasarkan laporan dan hasil survei dari Asosiasi penyelenggara Jasa Internet Indonesia (APJII) mengenai perilaku pengguna internet di Indonesia tahun 2017 menembus angka 143,26 juta dari total populasi penduduk sebanyak 262 juta orang. Hal ini dapat dilihat pada gambar 1.1 :

Tahun 2018 ini kebanyakan masyarakat Indonesia tidak lagi dapat melepaskan diri dari kegiatan komunikasi berbasis internet. Sejak awal pemerintahan Indonesia mengembangkan infrastruktur internet, jumlah pengguna internet terus meningkat dari tahun ke tahun. Hal ini dapat dilihat dari gambar 1.2 :

Berdasarkan laporan tersebut, APJII mencatat pengguna internet tertinggi berdasarkan wilayah. Jumlah pengguna internet di Jawa mencapai $58,08 \%$ dari total pengguna di Indonesia. Posisi kedua ditempati oleh wilayah Sumatera dengan jumlah pemakai internet mencapai $19,05 \%$, posisi ketiga ditempati oleh Kalimantan dengan jumlah pengguna 7,97\%. Posisi keempat disusul Sulawesi dengan jumlah pengguna 6,73\%. Posisi kelima bertengger Bali dan Nusa Tenggara persentase pengguna internetnya baru $5,63 \%$ dari jumlah total populasi. Posisi terakhir adalah wilayah Maluku dan Papua pengguna internet di wilayah ini hanya $2,49 \%$. Hal ini dapat dilihat pada gambar 1.3 :

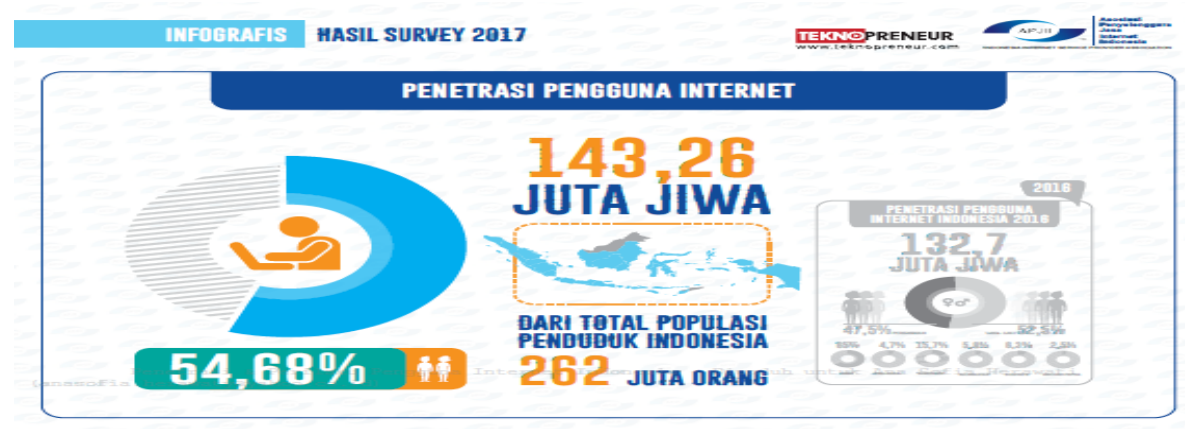

Gambar 1.1 Data Pengguna Internet di Indonesia

Sumber : data primer diolah 2018

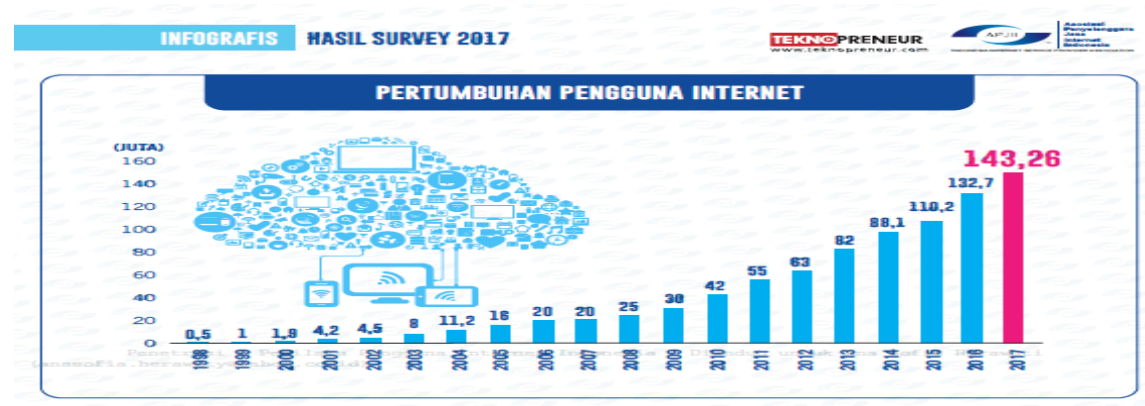

Gambar 1.2 Data Pertumbuhan Internet di Indonesia 
Sumber : data primer diolah 2018

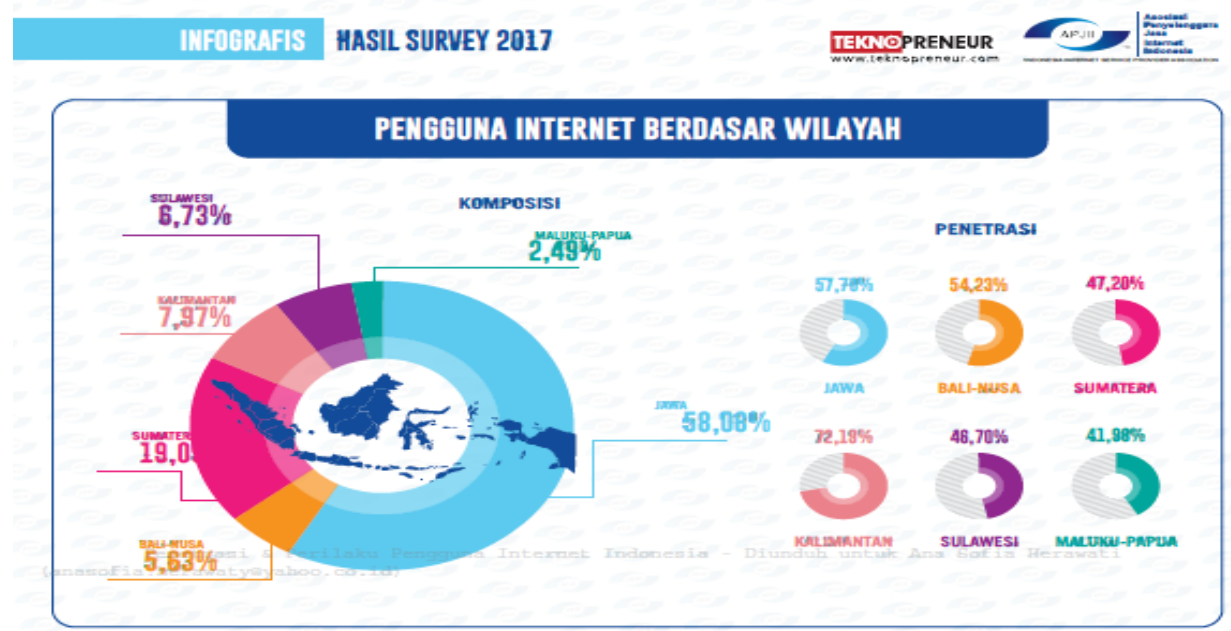

Gambar 1.3 Data Pengguna Internet Berdasarkan Wilayah

Sumber : data primer diolah 2018

Pengguna layanan internet juga masih didominasi oleh laki-laki. Dari 143,26 juta pengguna sebanyak $51,43 \%$ berjenis kelamin laki-laki sedangkan pengguna perempuan sebanyak $48,57 \%$. Hal ini dapat dilihat pada gambar 1.4 :

Lajunya perkembangan internet di Indonesia memberikan pengaruh yang sangat signifikan dalam segala bidang dan aspek kehidupan kita. Perkembangan teknologi informasi yang canggih memberikan kemudahan bagi setiap orang dalam melakukan berbagai transaksi, tidak hanya terbatas pada pemanfaatan informasi melalui media namun juga sebagai sarana transaksi perbankan. Saat ini banyak bank di Indonesia mulai memasuki dunia maya melalui internet banking. Bentuk layanan perbankan melalui media internet pada dasarnya merupkan transaksi perbankan antara pihak bank dengan nasabahnya yang dimediasi oleh media internet dan media elektronik.

Perkembagan internet yang sangat pesat mendorong dunia perbankan untuk ikut andil dalam memanfaatkan internet. Hal ini menjadi kesempatan bagi dunia perbankan untuk dapat melangkah maju dalam memberikan pelayanan yang lebih baik kepada para nasabahnya. Pelayanan internet banking tidak hanya berlaku bagi para pebisnis namun juga bagi masyarakat umum sebagai nasabah bank. Masyarakat menginginkan kemudahan dalam pelayanan perbankan untuk keperluan sehari-hari seperti untuk pembayaran tagihan listrik, air, telepon, transfer ke rekening lain dan lainnya melalui internet dengan website milik bank yang dilengkapi sistem keamanan.

Pengembangan terhadap kualitas layanan internet banking juga harus diimbangi dengan pengetahuan nasabah mengenai penggunaan internet banking. Hal ini sangat berpengaruh bagi nasabah dalam hal minat pengguna internet banking, sehingga perbankan harus bekerja keras untuk memberikan informasi kepada nasabah mengenai penggunaan dari internet banking.

\section{TINJAUAN PUSTAKA}

Pengetahuan Nasabah 
Kotler (2002:89) mendifinisikan pengetahuan adalah suatu perubahan dalam perilaku suatu individu yang berasal dari pengalaman. Pengetahuan merupakan hasil dari tahu, dan ini terjadi setelah orang melakukan penginderaan terhadap suatu objek tertentu. Penginderaan terjadi melalui panca indera manusia, yaitu indera penglihatan, pendengaran, penciuman, rasa dan raba. Sebagian besar pengetahuan manusia diperoleh melalui mata dan telinga (Notoatmodjo, 2007 : 76).

Menurut Notoatmodjo (2007:79) indikator pengetahuan nasabah adalah tahu (know), memahami (comprehension), aplikasi (application), analisis (analysis), sintesis (synthesis), dan evaluasi (evaluation).

\section{Kualitas Layanan}

Ruslan (2005:100) dalam konsep service of excellent membagi empat pokok unsur pelayanan yaitu kecepatan, ketepatan, keramahan, dan kenyamanan. Keempat unsur tersebut merupakan kesatuan palayanan jasa yang terintegrasi, sehingga apabila salah satu tidak terpenuhi maka pelayanan atau jasa yang diberikan dinilai tidak baik.

Kualitas layanan merupakan kunci keberhasilan dalam berbagai usaha atau kegiatan yang bersifat jasa. Bank sebagai lembaga keungan harus memiliki pelayanan yang baik untuk menumbuhkan minat terhadap produk-produknya. Menurut Moenir (2002:190) adalah pelayanan dengan lisan, pelayanan melalui tulisan, dan pelayanan dalam bentuk perbuatan.

Kualitas layanan menurut Sangadji dan Sopiah (2013:100) mempunyai lima macam indikator keandalan (reliability), daya tanggap (responsiviness), jaminan (assurance), empati (emphaty), dan produkproduk fisik (tangibles).

\section{Minat Pengguna}

Penerimaan penggunaan adalah keyakinan yang menonjol yang dimiliki nasabah untuk meyakini karakteristik tentang objek sehingga mengambil keputusan untuk menggunakannya (Adesina, 2010:04). Menurut Rita Waczuch et al (2007: 206-215), indikator -indikator minat pengguna adalah innovativeness, discomfort, dan optimism, insecurity.

\section{METODE PENELITIAN}

Jenis Penelitian

Jenis data yang digunakan dalam penelitian ini terbagi dua, yaitu data primer dan data sekunder. Data primer diperoleh langsung dari kuesioner yang telah dibagikan kepada nasabah Bank Bank X di Banjarmasin. Sedangkan data sekunder berupa data yang diperoleh secara tidak langsung berupa dokumentasi maupun kepustakaan dari buku literatur yang ada dan media internet.

Populasi dan Ukuran Sampel Penelitian

Populasi dalam penelitian ini adalah nasabah dari Bank Bank X di Banjarmasin dengan jumlah sampel 60 orang. Teknik pengambilan sampel yang digunakan dalam penelitian ini adalah stratified random sampling. Kasjono \& Yasril (2009:33) mengemukakan bahwa pengambilan sampel acak stratifikasi adalah suatu metode pengambilan sampel dimana populasi yang bersifat heterogen dibagi-bagi dalam lapisanlapisan (strata) yang saling pisah tuntas, dan dari setiap strata dapat diambil sampel secara acak.

\section{Teknik Pengumpulan Data}

Jenis data yang digunakan dalam penelitian ini terbagi dua, yaitu data primer dan data sekunder. Data primer diperoleh langsung dari kuesioner yang telah dibagikan kepada nasabah Bank Bank X di Banjarmasin. Sedangkan data sekunder berupa data yang 
diperoleh secara tidak langsung berupa dokumentasi maupun kepustakaan dari buku literatur yang ada dan media internet.

\section{Metode Analisis Data}

Analisis inferensial ditujukan untuk mengkaji hipotesa yang diajukan dalam penelitian, yaitu dengan menggunakan Metode Regresi Linear Berganda dan secara keseluruhan analisis data dilaksanakan dengan menggunakan program komputer statistik SPSS for windows.

Rumus persamaan regresi yang digunakan adalah :

$$
Y=a+b 1 X 1+b 2 X 2+e
$$

Keterangan :

$$
\begin{aligned}
\mathrm{a}= & \text { Intersep } \\
\mathrm{bn}= & \text { Koefisien regresi variabel } \\
& \text { Independent } \mathrm{N} \\
(\mathrm{Y})= & \text { Minat Pengguna } \\
(\mathrm{X} 1)= & \text { Pengetahuan Nasabah } \\
(\mathrm{X} 2)= & \text { Kualitas Layanan } \\
\mathrm{e}= & \text { Variabel lain yang tidak termasuk } \\
& \text { dalam model }
\end{aligned}
$$

Untuk menguji keabsahan persamaan regresi yang berkaitan dengan hipotesis yang diajukan, maka teknik ujinya dengan F-test dan T-test.

\section{HASIL DAN PEMBAHASAN}

Hasil
Dalam penelitian ini menggunakan model regresi berganda (Multiple Regression) untuk melihat pengaruh variabel bebas (Independent Variable) yaitu variabel pengetahuan nasabah dan kualitas layanan dengan variabel terikat (Dependent Variable) yaitu variabel minat pengguna.

Berdasarkan hasil perhitungan komputer program SPSS dengan memperhatikan besarnya koefisien korelasi $(\mathrm{R})$ sebesar 0,603 maka dapat dinyatakan bahwa hubungan antara pengetahuan nasabah dan kualitas layanan secara simultan adalah sangat kuat positif terhadap minat pengguna.

Berdasarkan hasil perhitungan didapat nilai F-hitung sebesar 16,298. Jadi dapat dinyatakan bahwa pengetahuan nasabah dan kualitas layanan secara simultan berpengaruh signifikan terhadap minat penggunaan internet banking.

Adapun besarnya pengaruh pengetahuan nasabah terhadap minat penggunaan internet banking menunjukkan pengaruh yang positif tetapi tidak signifikan sebesar 0.142 . Pengaruh kualitas layanan terhadap minat penggunaan internet banking menunjukkan pengaruh yang positif dan signifikan sebesar 0.406 .

Tabel 1. Kebaikan Model

\begin{tabular}{|c|r|r|r|r|}
\hline Model & \multicolumn{1}{|c|}{$\mathrm{R}$} & R Squere & $\begin{array}{c}\text { Adjusted R } \\
\text { Square }\end{array}$ & $\begin{array}{c}\text { Std. Error of } \\
\text { the Estimate }\end{array}$ \\
\hline 1 &, $603^{\mathrm{a}}$ &, 364 &, 333 & 1,567 \\
\hline
\end{tabular}

a. Predictors : (Constant), Kualitas Layanan, Pengetahuan Nasabah

b. Dependent Variable : Minat Pengguna 
Tabel 2. Uji Serentak

\begin{tabular}{|ll|r|r|r|r|r|}
\hline Model & Sum of Squares & df & Mean Square & F & Sig. \\
\hline 1 & Regression & 80,038 & 2 & 40,019 & 16,298 &, $000^{\mathrm{a}}$ \\
& & & & & & \\
& Residual & 139,962 & 57 & 2,455 & & \\
& Total & 220,000 & 59 & & & \\
\hline
\end{tabular}

a. Predictors: (Constant), Kualitas Layanan, Pengetahuan Nasabah

b. Dependent Variable: Minat Pengguna

Tabel 3. Uji Parsial

\begin{tabular}{|c|c|c|c|c|c|c|c|}
\hline \multirow[t]{2}{*}{ Model } & \multicolumn{2}{|c|}{$\begin{array}{l}\text { Unstandardized } \\
\text { Coefficients }\end{array}$} & \multirow{2}{*}{$\begin{array}{c}\text { Standardized } \\
\text { Coefficients } \\
\text { Beta }\end{array}$} & \multirow[b]{2}{*}{$\mathrm{t}$} & \multirow[b]{2}{*}{ Sig. } & \multicolumn{2}{|c|}{$\begin{array}{c}\text { Collinearity } \\
\text { Statistics }\end{array}$} \\
\hline & B & $\begin{array}{l}\text { Std. } \\
\text { Error }\end{array}$ & & & & Tolerance & VIF \\
\hline (Constant) & 4,787 & 2,149 & & 2,227 & ,030 & & \\
\hline $\begin{array}{l}\text { Pengetahuan } \\
\text { Nasabah }\end{array}$ &, 142 & 108 & ,204 & 1,316 & , 194 & ,463 & 2,161 \\
\hline $\begin{array}{l}\text { Kualitas } \\
\text { Layanan }\end{array}$ & 406 & 144 & ,437 & 2,815 & ,007 & ,463 & 2,161 \\
\hline
\end{tabular}

a. Dependent Variable: Minat Pengguna

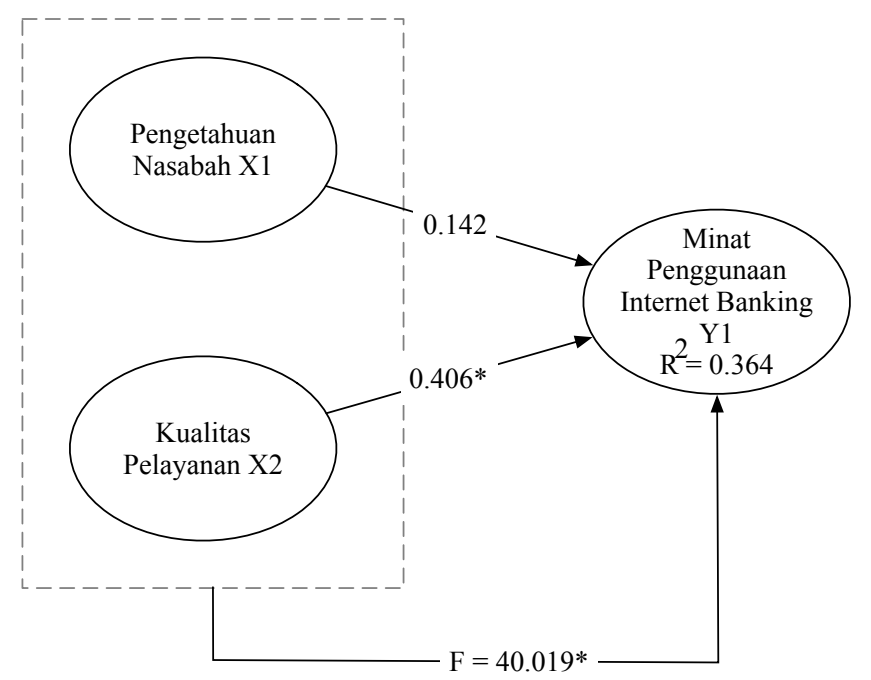

Gambar 3. Hasil Pengujian Model

\section{Pembahasan}

Pengetahuan nasabah berpengaruh secara signifikan terhadap minat pengguna internet banking di Banjarmasin sehingga membuktikan teori Kotler (2002:89), secara teoritis dapat dinyatakan bahwa pengetahuan nasabah sangat penting bagi minat pengguna internet banking di Banjarmasin. Semakin ditingkatkan pengetahuan nasabah, maka akan mampu meningkatkan minat pengguna.

Kualitas layanan berpengaruh secara signifikan terhadap minat pengguna internet banking di Banjarmasin sehingga membuktikan teori Ruslan (2005:100), secara 
teoritis dapat dinyatakan bahwa kualitas layanan sangat penting bagi minat pengguna internet banking di Banjarmasin. Semakin ditingkatkan kualitas layanan, maka akan mampu meningkatkan minat pengguna internet banking.

\section{KESIMPULAN DAN SARAN}

Kesimpulan

Berdasarkan hasil pengujian hipotesis dan pembahasan yang telah dilakukan, maka dapat ditarik kesimpulan bahwa hasil tanggapan responden melalui pengisian kuesioner dan hasil analisis deskriptif menyatakan bahwa sebagian besar responden setuju terhadap pengetahuan nasabah dapat meningkatkan minat pengguna, setuju terhadap adanya kualitas layanan untuk meningkatkan minat pengguna, dan setuju bahwa minat pengguna dipengaruhi oleh pengetahuan nasabah dan kualitas layanan. Pengetahuan nasabah berpengaruh secara signifikan dan dengan arah positif terhadap minat pengguna, adapun besarnya pengaruh pengetahuan nasabah terhadap minat pengguna internet banking ialah sebesar $27,5 \%$ dan sisanya sebesar $72,5 \%$ minat pengguna dipengaruhi oleh faktor lain. Kualitas layanan berpengaruh secara signifikan terhadap minat pengguna, adapun besarnya pengaruh kualitas layanan terhadap minat pengguna internet banking ialah sebesar $34,4 \%$ dan sisanya sebesar $65,6 \%$ minat pengguna dipengaruhi oleh faktor lain.Pengetahuan nasabah dan kualitas layanan secara simultan berpengaruh secara signifikan terhadap minat pengguna internet banking sebesar $36,4 \%$.

Saran

Dari kesimpulan di atas dapat dikemukakan saran-saran sebagai berikut; Jika pengetahuan nasabah dan kualitas layanan terhadap minat pengguna internet banking ditingkatkan akan semakin baik dan positif, sebaliknya jika pengetahuan nasabah dan kualitas layanan terhadap minat pengguna internet banking kurang (minim) maka minat pengguna internet banking akan rendah. Sebesar $66 \%$ faktor lain yang mempengaruhi minat pengguna internet banking dari hasil analisis parsial pengetahuan nasabah dan kualitas layanan, sehingga perlu dikembangkan lagi penelitian tentang minat pengguna internet banking selanjutnya. Dari hasil analisis secara simultan hampir 34\% pengetahuan nasabah dan kualitas layanan memiliki pengaruh yang besar terhadap minat pengguna, sehingga untuk penelitian di masa yang akan datang perlu dikembangkan lagi faktor apa saja yang mempengaruhi minat pengguna selain pengetahuan nasabah dan kualitas layanan.

\section{DAFTAR PUSTAKA}

Ambarita, R. (27 September 2012). Anggap Karyawan Aset, Kunci Sukses Perusahaan.

http://www.kabarbisnis.com/read/28335 44

Dessler, G. (2009). Manajemen Sumber Daya Manusia. Jakarta : Index.

Dessler, Gary(2015). Human Resources Management (Manajemen Sumber Daya Manusia), Ed. 14. Edisi Bahasa Indonesia. Jakarta: Indeks.

George, J.M. \& Jones, G.R. (2005). Understanding And Managing organizational behavior (4th ed.). New Jersey: Upper Saddle River Whetten, D.A., and Cameron, K.S. (2011). Developing management skills (8th ed.). New Jersey: Upper Saddle River.

Hasibuan, Malayu S.P. 2008. Manajemen Sumber Daya Manusia. Jakarta : Bumi 
Aksara.

Hasibuan(2014). Manajemen Sumber Daya

Manusia. Bandung: Bumi Aksara.

Imam Ghozali, Aplikasi Analisis, hlm. 147.

Mangkunegara, A.P. (2005). Evaluasi Kinerja

Sumber Daya Manusia. Cetakan I.

Bandung: PT Refika Aditama.

-----------. (2006). Manajemen Sumber

DayaManusia. Remaja Rosdakarya.

Bandung.

Mangkunegara, A.P. (2014). Manajemen

Sumber Daya Manusia Perusahaan.

Jakarta: PT. Rajagrafindo Persada.

Marwansyah. 2014. Manajemen Sumber

Daya Manusia. Bandung: Alfabeta.

Rivai, Veithzal danSagala,Ella Jauvani (2014), Manajemen Sumber Daya Manusia Untuk Perusahaan, Ed. 3. Jakarta: PTRajawali press.
Raymond, A., Noe., John, R., Hollenbeck., Barry, G. \&Patrick, M.W. (2008). Human Resources Management : Gaining A Competitive Advantage, 6th Edition, McGrawHill/Irwin.

Sedarmayanti. 2013. Manajemen Sumber Daya Manusia. Bandung : PT Refika Aditama.

Sunyoto, D. (2012). Teori, Kuisioner Dan Analisis Data Sumber Daya Manusia. Yogyakarta: CAPS.

Sutrisno, Edy. 2009. Manajemen Sumber Daya Manusia. Kencana Prenada Media Grup. Jakarta.

Wijonarko. (27 September 2012). Anggap Karyawan Aset, Kunci Sukses Perusahaan.

http://www.kabarbisnis.com/read/28335 44 